\title{
Determination of pH-dependent antioxidant activity of palm (Borassus flabellifer) polyphenol compounds by photoluminol and DPPH methods: a comparison of redox reaction sensitivity
}

\author{
Satyabrata Ghosh • Runu Chakraborty • \\ Utpal Raychaudhuri
}

Received: 24 November 2013/Accepted: 7 October 2014/Published online: 19 October 2014

(C) The Author(s) 2014. This article is published with open access at Springerlink.com

\begin{abstract}
Palm juice (Borassus flabellifer) is one of the most common and cheap natural juices. Fermented palm juice contains various phytochemical compounds that exhibit antioxidant activity. In the present study, we examined the effects of $\mathrm{pH}$ on the production of phytochemicals and their antioxidant activity during the fermentation process. The concentration of total phenolics and flavonoid compounds of fermented palm juice and their antioxidant activity were investigated at various $\mathrm{pH}$. The results showed that total phenolics concentration and antioxidant activity of palm wine and palm vinegar increase as $\mathrm{pH}$ increases: $3.5<4.5<5.5$. Maximum flavonoid concentration was obtained at $\mathrm{pH}$ 6.5. Measurements of antioxidant activity by conventional DPPH method and Photochem antioxidant analyzer technique were highly correlated, with a corresponding $R^{2}$ value of 0.94 .
\end{abstract}

Keywords Antioxidant activity - Antioxidant analyzer · DPPH $\cdot$ Fermentation $\cdot$ Palm juice

\section{Introduction}

In recent years, researchers have found that fresh fruits and vegetables significantly contribute to reduction of

\footnotetext{
S. Ghosh $(\square)$

Department of Ingeniería Rural ETSI Agrónomos, Universidad Politecnica de Madrid, Madrid, Spain

e-mail: satyabrataghosh23@gmail.com

R. Chakraborty · U. Raychaudhuri ( $₫)$

Department of Food Technology and Biochemical Engineering, Jadavpur University, Kolkata 700032, India

e-mail: urcfoodtech@yahoo.co.in
}

cardiovascular disease and some types of cancer. Therefore, attempts are being made to correlate epidemiology studies with analysis of normal diets (Ames 1983; Eberthardt et al. 2000; Namiki 1990; Osawa et al. 1990). Fruits and vegetables contain active components including nutrients that contribute to the protection of our body (Dragsted 2003; Hertog et al. 1993; Yang et al. 2001). Antioxidants in food are thought to prevent chronic conditions by preventing damage to important bio-molecules such as DNA, proteins, lipids, etc. (Willcox et al. 2004). Antioxidant compounds are also found in fermented products. In fact, studies have shown that fermentative products are enriched with higher antioxidant activity than their non-fermentative counterparts (Esaki et al. 1997; Lin et al. 2006). Several microorganisms function as natural antioxidant factories (Ishikawa 1992); their antioxidative metabolites (Lin and Yen 1999) produce high free radical scavenging activity (Abe et al. 1998). Yeast is one of these microorganisms that has been shown to increase antioxidant activity of fermented products (Gazi et al. 2001). Yeast produces various enzymes during the fermentation process that have been shown to yield strong antioxidant activity, such as $\beta$-glucosidase, carboxyl esterase, feruloyl esterase, etc., (Coghe et al. 2004; Hernandez et al. 2003). Acetobacter aceti is another particularly important and commercially viable microorganism in this class. Because this organic compound produces acetic acid, it is commonly used in the production of natural vinegars containing beneficial organic acids, vitamins, phenolic acids, flavonoids and other nutrients showing high antioxidant activity.

The stability and free radical scavenging activity of polyphenol compounds depend on the surrounding $\mathrm{pH}$ of the reaction environment (Swiglo and Muzolf 2007). The polyphenol compounds possess various dissociable $-\mathrm{OH}$ 
groups in their chemical structure. It is logical to suspect that the $\mathrm{pH}$ of the surrounding medium will influence dissociation rates of the $-\mathrm{OH}$ groups in these polyphenol compounds, since previous studies have observed $\mathrm{pH}$ influencing the rate of dissociation of oxygen-containing chemical groups in hydroxyflavones and anthocyanins (Muzolf et al. 2008; Lemańska et al. 2001; Borkowski et al. 2005). Free radical scavenging activity would also be expected to change with $\mathrm{pH}$ changes. This latter possibility is particularly interesting in the case of palm wine and palm vinegar polyphenol compounds. Palm wine and palm vinegar fermentation is a biological process involving microbes that produce secondary metabolites that are also affected by the $\mathrm{pH}$ of the fermenting medium. It is important to study the effects of $\mathrm{pH}$ on antioxidant activity in precise experimental settings because of the varying $\mathrm{pH}$ environments present during food consumption and digestion. Antioxidant activity could be expected to change as food materials pass through different human body fluids of different $\mathrm{pH}: \mathrm{pH} 1$ in the stomach, $\mathrm{pH} 5.3$ in the small intestine, $\mathrm{pH} 6.8$ in mouth saliva, $\mathrm{pH} 7.4$ in blood and tissue fluid, $\mathrm{pH} 8$ in the large intestine, $\mathrm{pH} 7-8.7$ in pancreas, and pH 8.3-9.3 in duodenum (Grzymisławski 2000).

In this study, a new technique for the measurement of antioxidant activity, called Photochem antioxidant analyzer, has been used. This technique is based on a combination of photochemical generation of radicals and chemiluminometric detection. The working principle of this instrument is optical excitation of a photosensitizer substance and subsequent detection of superoxide anion radicals by means of a chemiluminogenic substance (luminol). Data from this antioxidant analyzer were compared with data collected from a conventional 2,2-diphenyl-1-picrylhydrazyl (DPPH) radical scavenging method.

The objective of this work is to monitor the effect of $\mathrm{pH}$ on the stability and antioxidant activity of polyphenol compounds in palm wine and palm vinegar produced by fermentation with Saccharomyces cerevisiae and A. aceti, respectively. The antioxidant activity, measured by a new Photochem technique, is also compared with the conventional DPPH method.

\section{Materials and methods}

\section{Chemicals}

Dextrose, glycerol (GR), $\mathrm{KH}_{2} \mathrm{PO}_{4}, \mathrm{~K}_{2} \mathrm{HPO}_{4}, \mathrm{MgSO}_{4} \cdot 7 \mathrm{H}_{2} \mathrm{O}$, $\mathrm{FeSO}_{4} \cdot 7 \mathrm{H}_{2} \mathrm{O}$, urea, HPLC grade water, HPLC grade methanol, Folin-Ciocalteu's phenol reagent, $\mathrm{AlCl}_{3}$, and $\mathrm{NaNO}_{2}$ were obtained from Merck, India. Yeast extract, peptone, 2,2-diphenyl-1 picrylhydrazyl (DPPH) were obtained from Himedia, India. Antioxidant Analyzer kit was obtained from Analytik Jena, Germany. (+) Catechin hydrate was obtained from Sigma-Aldrich, USA. Gallic acid was obtained from SD Fine Chem Ltd, India.

Microorganism and culture preparation

\section{Yeast and Acetobacter aceti culture preparation}

Stock culture of S. cerevisiae (NCIM 3045) and A. aceti (NCIM 2251) was procured from National Chemical Laboratory (NCL), Pune, India. The culture media of yeast consisted of 0.3 malt extract, 1.0 glucose, 0.3 yeast extract and 0.5 peptone (all in $\mathrm{g} / 100 \mathrm{~mL}$ ). The organisms were grown at $30{ }^{\circ} \mathrm{C}$ and $\mathrm{pH} 6.5$ for an incubation period of $48 \mathrm{~h}$. For A. aceti, the media composition was 1.0 tryptone, 1.0 yeast extract, 1.0 glucose, 1.0 calcium carbonate, and 2.0 agar (all in $\mathrm{g} / 100 \mathrm{~mL}$ ). The organisms were grown at $30{ }^{\circ} \mathrm{C}$ and $\mathrm{pH} 6.0$ for an incubation period of $24 \mathrm{~h}$.

\section{Fermentation media}

\section{Sample collection}

Palm juice (Borassus flabellifer) was randomly collected from local traders in rural areas of South 24 Parganas District, West Bengal, India. Traders harvested the palm juice after $12 \mathrm{~h}$ of collection in a mud jar through a tapping process using a bamboo tube. After purchase, the bottles of palm juice were kept in a refrigerator. During transportation time (2-3 h), the bottles were carried with ice bags and brought to our laboratory. In the laboratory, the palm juice was preserved at $-50{ }^{\circ} \mathrm{C}$ in an ultra low temperature freezer (Model C340, New Brunswick Scientific, England).

\section{Preparation of fermentation media for wine production}

For ethanol fermentation, carbon, nitrogen and other trace elements were added to the palm juice at the appropriate level. The proper composition of fermentation media as described in detail by Ghosh et al. (2012a) was closely followed.

Fermentation was done in a $250 \mathrm{~mL}$ flask. $100 \mathrm{~mL}$ of fermentation media was taken and the $\mathrm{pH}$ was adjusted to 3.5 , $4.5,5.5$ and 6.5 before being autoclaved. Then, the media were inoculated with $1 \mathrm{~mL}$ yeast culture (concentration of yeast cells in OD was 1.0) and kept at $32{ }^{\circ} \mathrm{C}$ for $96 \mathrm{~h}$. The flask was made airtight by paraffin paper to maintain anaerobic conditions. The samples were withdrawn for analysis at designated time intervals with a sterile injection syringe.

\section{Preparation of fermentation media for vinegar production}

After wine fermentation, sterile sugar (sucrose) was added to the media on the optimized condition and inoculated with 
$2 \mathrm{~mL}$ of an A. aceti starter culture solution. The concentration of the A. aceti in fermentation media was $\left(1.2 \times 10^{5}\right.$ cells $/ \mathrm{mL})$. The temperature and $\mathrm{pH}$ were $30{ }^{\circ} \mathrm{C}$ and $3.5,4.5$, 5.5 and 6.5 , adjusted with $1 \mathrm{~N} \mathrm{HCl}$ solution and (1:1) aqueous ammonia solution as per experiments at sterile conditions. The incubation time was $96 \mathrm{~h}$ and aerobic conditions were maintained by shaking at 150 RPM. The samples were withdrawn for analysis at designated time intervals with a sterile injection syringe (Ghosh et al. 2012b).

\section{Sample preparation}

The fermented sample was withdrawn at appropriate time intervals and then centrifuged at 3,000 RPM for $20 \mathrm{~min}$. The supernatant was collected and filtered with Whatman filter paper no. 1 for the subsequent analytical purpose.

\section{Alcohol estimation}

$5 \mathrm{~mL}$ of fermented sample was centrifuged (Remi C-24, Mumbai, India) at 3,500 RPM for $10 \mathrm{~min}$. The supernatant solution was used to determine the ethanol concentration by Gas chromatography (Perichrom SGE D11, column BP1-dimethyl polysiloxane).

\section{Acid estimation}

Acetic acid concentration was quantified by an HPLC system (JASCO, MD-2015 Plus Multi wavelength Detector) equipped with absorbance detectors set to $210 \mathrm{~nm}$. The column (ODS-3) was eluted with $0.01(\mathrm{~N}) \mathrm{H}_{2} \mathrm{SO}_{4}$ as a mobile phase, at a flow rate of $0.5 \mathrm{~mL} / \mathrm{min}$, and sample injection volume of $20 \mu \mathrm{L}$. Standard acetic acid (Merck, India) was used as an external standard.

\section{Determination of total phenolics content}

Using Folin-Ciocalteu (FC) reagent, the total phenolics content (TPC) was measured according to the method (Di Stefano and Guidoni 1989; Singleton et al. 1999). In a spectrophotometer cuvette, an aliquot of $20 \mu \mathrm{L}$ samples was taken along with $150 \mu \mathrm{L}$ of Folin-Ciocatlteu reagent, $600 \mu \mathrm{L}$ of a $15 \% \mathrm{Na}_{2} \mathrm{CO}_{3}$ solution, and a final volume filled to $3,000 \mu \mathrm{L}$ with distilled water. After $2 \mathrm{~h}$, the increase in absorbance was measured at $784 \mathrm{~nm}$ and the concentrations of TPC, expressed as $\mathrm{mg} / \mathrm{L}$ catechin equivalent (CE), were determined by a calibration curve graph.

Determination of total flavonoids content

Total flavonoid content (TFC) was measured by aluminum chloride colorimetric assay (Zhishen et al. 1999). An aliquot of $1 \mathrm{~mL}$ sample extract or standard solution of catechin was taken in a $10 \mathrm{~mL}$ volumetric flask containing $4 \mathrm{~mL}$ of distilled water. $0.3 \mathrm{~mL}$ of $5 \% \mathrm{NaNO}_{2}$ was added to the flask. After $5 \mathrm{~min}, 0.3 \mathrm{~mL}$ of $10 \% \mathrm{AlCl}_{3}$ was added. At the 6th min, $2 \mathrm{~mL}(1 \mathrm{M}) \mathrm{NaOH}$ was added and the total volume was then filled to $10 \mathrm{~mL}$ with distilled water. The solution was mixed well and the absorbance was measured against a prepared reagent blank at $510 \mathrm{~nm}$. Total flavonoid content was expressed as $\mathrm{mg} / \mathrm{L}$ catechin equivalent.

\section{Determination of DPPH radical scavenging activity}

The effect of the sample on DPPH radical was estimated according to the procedure described by Brand-Williams et al. (1995). The sample $(0.1 \mathrm{~mL})$ was added to $3.9 \mathrm{~mL}$ of DPPH $(100 \mu \mathrm{M})$ in ethanol that was prepared daily. The absorbance was determined at $515 \mathrm{~nm}$ after incubation for $45 \mathrm{~min}$. The $0.1 \mathrm{~mL}$ ethanol solution and $3.9 \mathrm{~mL}$ of DPPH solution were used as control and only ethanol was used as blank. The inhibitory percentage of DPPH was calculated according to the following Eq. (1):

$$
\begin{aligned}
& \text { Scavenging effect }(\% \text { of inhibition }) \\
& \quad=\left[1-\left(\text { absorbance }_{\text {sample }} / \text { absorbance }_{\text {control }}\right)\right] \times 100
\end{aligned}
$$

Determination of antioxidant activity by photoluminol method

Antioxidant activity was measured by Photochem (Analytik Jena, Germany) using an antioxidant kit (Zhai et al. 2003). The kit was comprised of reagent 1 , reagent 2 , reagent 3 and reagent 4 . Reagent 1 was water, reagent 2 buffer solution, and reagent 3 photoluminating agent. The working solution was prepared by adding $750 \mu \mathrm{L}$ of reagent 2 to a stock solution of reagent 3 . It was mixed well on a vortex and used for further experiment. Reagent 4 was ascorbic acid; its stock solution was prepared by mixing $490 \mu \mathrm{L}$ of reagent 1 and $10 \mu \mathrm{L} 95 \% \mathrm{H}_{2} \mathrm{SO}_{4}$ into a vial containing reagent 4 . The resulting solution was mixed well on a vortex for $20-30 \mathrm{~s}(10 \mathrm{nmol} / \mathrm{L})$. Then, a reagent 4 working solution was prepared by adding $10 \mu \mathrm{L}$ of reagent 4 stock solution to $990 \mu \mathrm{L}$ of reagent 1 . The blank was prepared with $1.5 \mathrm{~mL}$ reagent $1,1.0 \mathrm{~mL}$ reagent 2 , and $25 \mu \mathrm{L}$ reagent 3 . The sample solution contained $(1.5-Y)$ $\mathrm{mL}$ reagent $1,1.0 \mathrm{~mL}$ reagent 2 , and $25 \mu \mathrm{L}$ reagent 3 , where $Y=5 \mu \mathrm{L}$ of sample.

Statistical analysis

Statistica Release 8 software (Statsoft, USA) was used for data analysis. All experiments were repeated three times and data were presented as mean $\pm \mathrm{SD}$ for three 


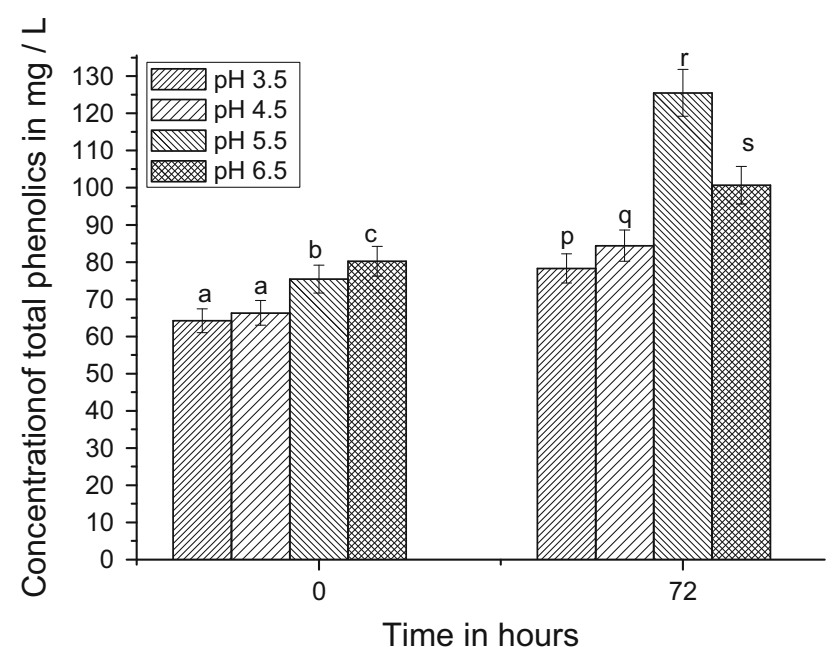

Fig. 1 Effect of $\mathrm{pH}$ on palm wine fermentation; measurement of total phenolics concentration

replications for each sample. The Fisher Least Significance Test was used to check the equality of variances and oneway ANOVA was used to estimate the statistically significant difference $(p \leq 0.05)$.

\section{Results}

The palm juice fermentation occurred through a two-step process: in the first, palm juice was converted to ethanol by S. cerevisiae; in the second, acetic acid was produced from ethanol by $A$. aceti. Both the fermentations occurred at optimum temperature and the best nutritional conditions, but variation in $\mathrm{pH}$ highly influenced the TPC, TFC and antioxidant activity of palm wine and palm vinegar.

Effect of $\mathrm{pH}$ on TPC, TFC and antioxidant activity in palm wine fermentation

$\mathrm{pH}$ has a significant impact on optimum yield in the fermentation processes. It also influences the structural stability and antioxidant activity of several phenolic acids and esters in polyphenol compounds. Our results show that the concentration of TPC increased gradually with time during the fermentation process for all $\mathrm{pH}$. At $0 \mathrm{~h}$ (before onset of the fermentation process), TPC was highest at $\mathrm{pH} 6.5$, and it was decreased with decreasing order of $\mathrm{pH}$ as $3.5<4.5<5.5<6.5$. But after $72 \mathrm{~h}$ fermentation, the maximum concentration of TPC $(125 \mathrm{mg} / \mathrm{L})$ was obtained at $\mathrm{pH}$ 5.5. The significance $(p \leq 0.05)$ of these maximum values is depicted in (Fig. 1).

It has been reported that TFC is more stable at higher $\mathrm{pH}$ (Lina et al. 2008). In Fig. 2, we show that at zero hour, the TFC concentration was the maximum at $\mathrm{pH}$ 6.5. The

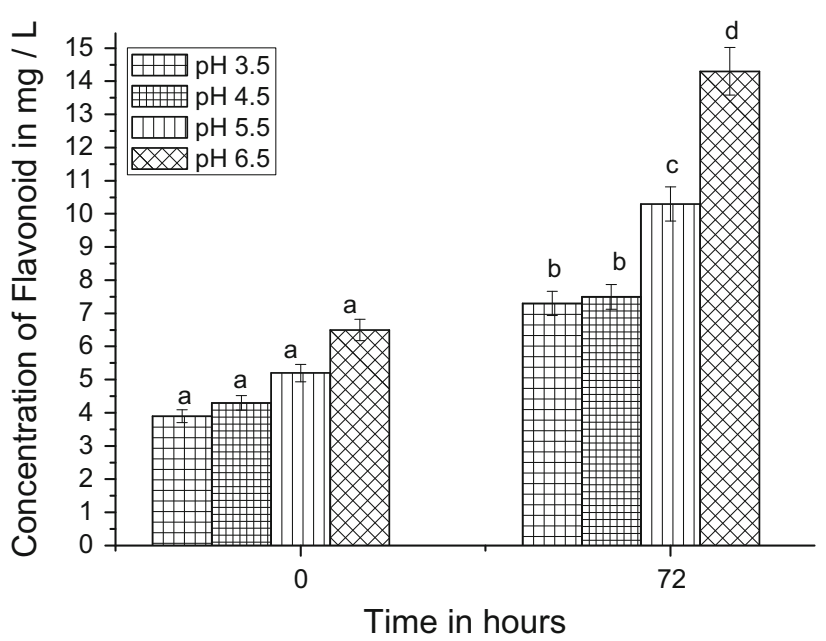

Fig. 2 Effect of $\mathrm{pH}$ on palm wine fermentation measurement of flavonoid concentration

maximum value of $\mathrm{pH} 6.5$ was $6.5 \mathrm{mg} / \mathrm{L}$; but this value was not significantly higher than that of the others. After $72 \mathrm{~h}$ fermentation, however, TFC was highest at $\mathrm{pH} 6.5$, but the concentration was $14.3 \mathrm{mg} / \mathrm{L}$, significantly higher than the values at other $\mathrm{pH}$.

Our results show that in palm wine fermentation (Table 1), antioxidant activity was increasing with $\mathrm{pH}$ up to $\mathrm{pH}$ 5.5, but dropped at $\mathrm{pH} 6.5$. At $\mathrm{pH}$ 6.5, antioxidant activity was lower than the value of $\mathrm{pH} 5.5$, but higher than values at other $\mathrm{pH}$. The radical scavenging activity test via DPPH and the Photochem method also showed the highest value at $\mathrm{pH}$ 5.5: the values were $127.39(\mathrm{mg} / \mathrm{L}$ of $\mathrm{CE})$ and $155(\mathrm{~m} / \mathrm{L}$ of AE), respectively. The maximum ethanol concentration was also obtained at $\mathrm{pH} 5.5$ (Table 1). Maximum values of TPC, TFC, antioxidant activity and ethanol concentrations were obtained after $72 \mathrm{~h}$ of fermentation, after which time values decreased.

Effect of $\mathrm{pH}$ on TPC, TFC and antioxidant activity in palm vinegar fermentation

During acetic acid fermentation, $\mathrm{pH}$ influences the biological activity of the A. aceti; therefore, optimum $\mathrm{pH}$ is considered as the one important factor for producing the highest yield of acetic acid production, as well as the microbial growth. After palm wine fermentation, the $\mathrm{pH}$ of the media was adjusted at varying ranges with $1(\mathrm{~N}) \mathrm{HCl}$ and 1:1 ammonia solution for acetic acid fermentation. The external $\mathrm{pH}$ adjustment at zero hour also reduced antioxidant activity along with TPC and TFC concentrations of the vinegar fermentation media. After the vinegar fermentation started, $\mathrm{pH} 5.5$ was found to be the optimum for highest acetic acid production $(68.29 \mathrm{~g} / \mathrm{L})$ (Table 2). The TPC concentration was highest at $\mathrm{pH} 5.5$ after $72 \mathrm{~h}$. 
Table 1 Qualitative and quantitative data of antioxidant compounds and antioxidant activity of palm wine (after $72 \mathrm{~h}$ of fermentation)

\begin{tabular}{llcccc}
\hline $\mathrm{pH}$ & Ethanol $(\mathrm{g} / \mathrm{L})$ & Total phenol $(\mathrm{mg} / \mathrm{L})$ & Total flavonoid $(\mathrm{mg} / \mathrm{L})$ & Antioxidant by DPPH $(\mathrm{mg} / \mathrm{L})$ & Antioxidant by analyzer $(\mathrm{mg} / \mathrm{L})$ \\
\hline 3.5 & $35.71 \pm 5.18^{\mathrm{a}}$ & $78.3 \pm 7.5^{\mathrm{e}}$ & $7.3 \pm 2.7^{\mathrm{aa}}$ & $91.81 \pm 2.8^{\mathrm{m}}$ & $113 \pm 5.4^{\mathrm{a}}$ \\
4.5 & $48.46 \pm 3.84^{\mathrm{b}}$ & $84.4 \pm 5.2^{\mathrm{f}}$ & $7.5 \pm 1.6^{\mathrm{aa}}$ & $93.33 \pm 2.6^{\mathrm{m}}$ & $120 \pm 5.5^{\mathrm{b}}$ \\
5.5 & $75.49 \pm 3.70^{\mathrm{d}}$ & $125.5 \pm 9.9^{\mathrm{h}}$ & $10.3 \pm 1.9^{\mathrm{cc}}$ & $127.39 \pm 3.1^{\mathrm{p}}$ & $155 \pm 6.1^{\mathrm{d}}$ \\
6.5 & $63.67 \pm 3.56^{\mathrm{c}}$ & $100.7 \pm 5.4^{\mathrm{g}}$ & $14.3 \pm 1.7^{\mathrm{dd}}$ & $106.95 \pm 2.5^{\mathrm{n}}$ & $131 \pm 4.1^{\mathrm{c}}$
\end{tabular}

Values represent mean of triplicates \pm standard deviation. Superscript means with different letters are significant different to each other in the same column $(p=0.05)$

Table 2 Qualitative and quantitative data of antioxidant compound and activity for palm juice vinegar produced from palm juice (after $72 \mathrm{~h}$ of fermentation)

\begin{tabular}{lllccc}
\hline $\mathrm{pH}$ & Acetic acid $(\mathrm{g} / \mathrm{L})$ & Total phenol $(\mathrm{mg} / \mathrm{L})$ & Total flavonoid $(\mathrm{mg} / \mathrm{L})$ & Antioxidant by DPPH $(\mathrm{mg} / \mathrm{L})$ & Antioxidant by analyzer $(\mathrm{mg} / \mathrm{L})$ \\
\hline 3.5 & $25.16 \pm 7.40^{\mathrm{a}}$ & $132 \pm 4.1^{\mathrm{f}}$ & $7.2 \pm 1.5^{\mathrm{ab}}$ & $83.22 \pm 2.1^{\mathrm{r}}$ & $78 \pm 4.3^{\mathrm{k}}$ \\
4.5 & $55.73 \pm 5.83^{\mathrm{b}}$ & $158 \pm 4.1^{\mathrm{g}}$ & $7.6 \pm 1.8^{\mathrm{ab}}$ & $89.09 \pm 1.2^{\mathrm{s}}$ & $104 \pm 3.4^{\mathrm{q}}$ \\
5.5 & $68.29 \pm 6.27^{\mathrm{c}}$ & $168 \pm 4.2^{\mathrm{h}}$ & $9.1 \pm 1.2^{\mathrm{ad}}$ & $102.27 \pm 2.4^{\mathrm{t}}$ & $125 \pm 5.4^{\mathrm{m}}$ \\
6.5 & $58.17 \pm 5.13^{\mathrm{d}}$ & $145 \pm 4.2^{\mathrm{i}}$ & $10.7 \pm 1.7^{\mathrm{bc}}$ & $88.84 \pm 2.3^{\mathrm{u}}$ & $93 \pm 3.1^{\mathrm{n}}$ \\
\hline
\end{tabular}

Values represent mean of triplicates \pm standard deviation. Superscript means with different letters are significant different to each other in the same column $(p=0.05)$

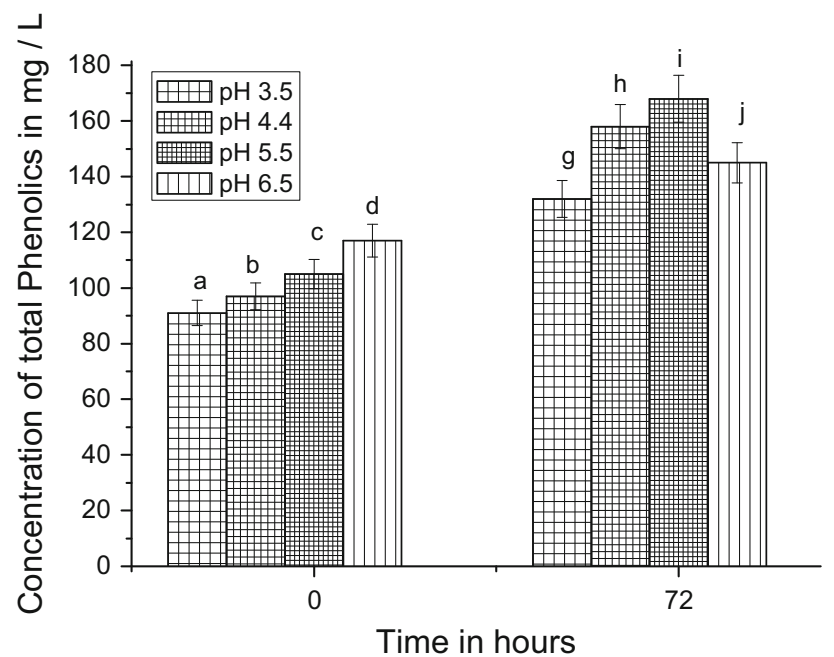

Fig. 3 Effect of pH on palm vinegar fermentation; measurement of total phenolics concentration

However, at the initial stage $(0 \mathrm{~h})$ of vinegar fermentation, the TPC was significantly higher at pH 6.5 (Fig. 3). But with an increase in time, TPC gradually increased for all $\mathrm{pH}$, with $\mathrm{pH} 5.5$ showing highest concentrations. At $\mathrm{pH}$ 5.5, TPC value was $168 \mathrm{mg} / \mathrm{L} ; \mathrm{pH} 4.5$ was in second position (Fig. 3).

Figure 4 shows that at the initial stage $(0 \mathrm{~h})$ of fermentation, the TFC of palm vinegar was highest at $\mathrm{pH} 6.5$ $(8.1 \mathrm{mg} / \mathrm{L})$. TFC was increased during acetic acid fermentation. After $72 \mathrm{~h}$, the maximum TFC was $10.7 \mathrm{mg} / \mathrm{L}$ at $\mathrm{pH} 6.5 ; \mathrm{pH} 5.5$ was second highest for TFC production $(9.1 \mathrm{mg} / \mathrm{L})$.

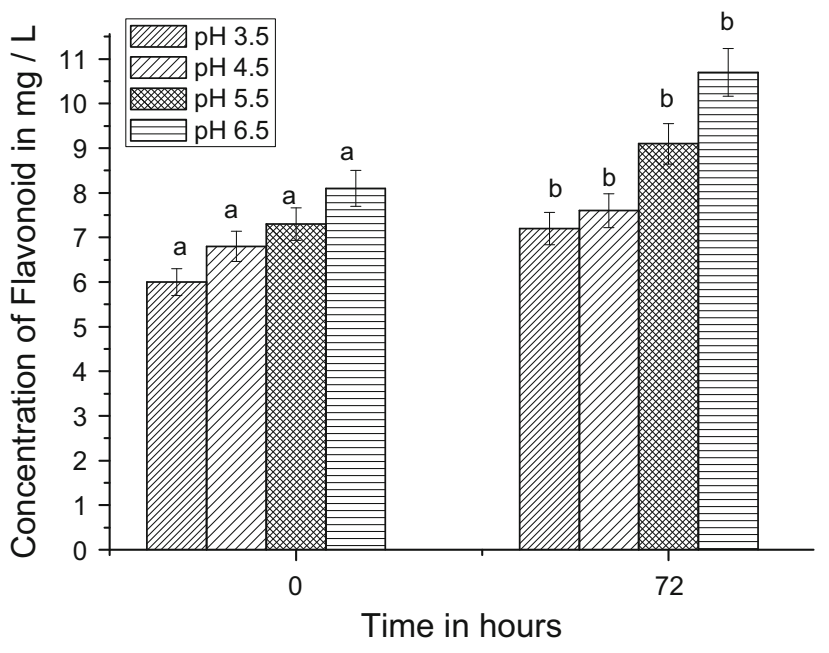

Fig. 4 Effect of $\mathrm{pH}$ on palm vinegar fermentation; measurement of total flavonoids concentration

As shown in Table 2, radical scavenging activity of palm vinegar by DPPH and Photochem method was maximized at $\mathrm{pH}$ 5.5: the values were $102.27(\mathrm{mg} / \mathrm{L}$ of CE) and $125(\mathrm{mg} / \mathrm{L}$ of AE), respectively. These values were significantly higher $(p \leq 0.05)$ compared to other $\mathrm{pH}$. For palm vinegar, maximum values of TPC, TFC and antioxidant acidity were obtained after $72 \mathrm{~h}$ of fermentation and after that all values were decreased with time.

Finally, after comparing the two fermented products (i.e., palm wine and palm vinegar), it can be shown that TPC concentration was higher in palm vinegar but that radical scavenging activity was higher in palm wine (Tables 1, 2). 


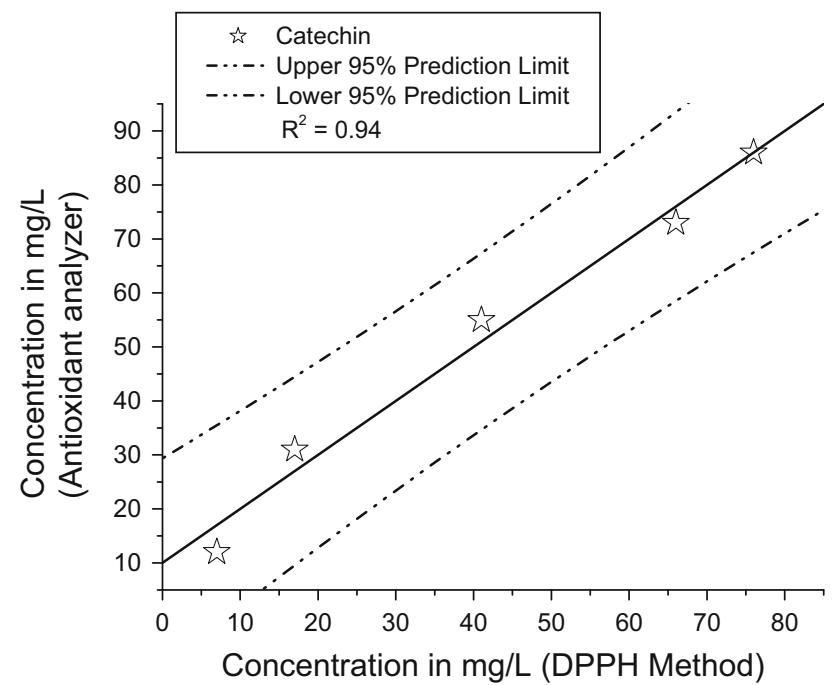

Fig. 5 Correlations between antioxidant activities analyzed by DPPH method and by an antioxidant analyzer

\section{Antioxidant activity measurement by Photochem}

A new technique was used for measurement of antioxidant concentration, the Photochem antioxidant analyzer. By this method, the concentration of antioxidant compounds in palm wine was found to be highest at $\mathrm{pH} 5.5$ $(155 \pm 6.0 \mathrm{mg} / \mathrm{L}$ of AE) (Table 1). For palm vinegar, the highest antioxidant concentration was $125 \mathrm{mg} / \mathrm{L}$ (of AE) at pH 5.5 (Table 2). The result of the analytical method was validated by linear correlation comparison between the DPPH method and the antioxidant analyzer method. The $R^{2}$ value is 0.94 (Fig. 5).

\section{Discussion}

Palm juice contains various nutrients (i.e., carbohydrate, protein amino acid, ascorbic acid, polyphenol, and flavonoid, etc.) and also shows antioxidant activity. The antioxidant properties are dependent on the $\mathrm{pH}$ of the medium, since changes in pKa values correspond to the change of ionization hydroxyl groups or other functional groups of the phenolic compounds (Amorati et al. 2006). Our results showed that the optimum $\mathrm{pH}$ for the highest yield of product formation in fermentation corresponded to a maximum concentration of TPC and antioxidant activity. Initially, the $1(\mathrm{~N}) \mathrm{HCl}$ solution reduced the TPC and TFC concentrations from raw palm juice, and this corresponded to reduced antioxidant activity. The reason for this is that antioxidant activity is influenced by $\mathrm{pH}$ in different ways: (1) electrochemical oxidation and $\mathrm{H}^{+}$involvement; (2) the torsion angle of one ring with the rest of the molecules was correlated with scavenging activity due to increased conjugation, which the planarity offers; (3) oxidation stability of the compound; and (4) transformation of the compound (Van Acker et al. 1996; Huang et al. 1996). Earlier researchers reported that antioxidant activity depends upon the oxidation rate of antioxidant compounds, and this oxidation rate was influenced by the surrounding pH (Jovanovic et al. 1994). The catechin showed little antioxidant activity below $\mathrm{pH} 5$, but activity increased above pH 6 (Midori et al. 2001). Physico-chemical properties of phenolics and flavonoid compounds of the raw palm juice should be expected to change due to the external $\mathrm{pH}$, and antioxidant activity should also be expected to reduce (Swiglo and Muzolf 2007). But during palm wine fermentation, yeast growth was affected by varying the $\mathrm{pH}$ of the medium: $\mathrm{pH} 5.5$ was optimum for metabolic activation of the yeast, producing the highest volume of metabolites, the highest antioxidant activity, and the maximum content of phenolics and flavonoids.

In the palm vinegar fermentation, the optimal $\mathrm{pH}$ for acetic acid production was $\mathrm{pH}$ 5.5. Acetobacter aceti showed optimal growth in these conditions. Palm vinegar also showed the highest antioxidant activity and TPC after $72 \mathrm{~h}$ at $\mathrm{pH}$ 5.5. From this observation, it can be concluded that this particular microbe produced a maximum amount of metabolites that are more stable at this $\mathrm{pH}$. But TFC was highest at $\mathrm{pH} 6.5$ in palm vinegar. It means that $A$. acetiproducing TPC is not flavonoid group-containing polyphenol compounds. For both fermentation steps, we have seen that the highest yield of product contained a maximum concentration of antioxidant compounds. This means that the concentration of total phenolics and antioxidant compounds not only depend on $\mathrm{pH}$, but also on the microorganisms' physiological status. At optimum $\mathrm{pH}$ conditions, microorganisms were more metabolically active; therefore, they were able to deliver the highest yield of product along with more secondary metabolites and other substances, which act as antioxidant compounds.

Another important observation was that while concentration of TPC was higher in palm juice vinegar than in palm wine, antioxidant activity was higher in palm wine (Tables 1,2). The reason behind this is protein: amino acids and other secondary metabolites produced by acetic acid bacteria interfere with the FC (Folin-Ciocalteu) reagent, which are not actual antioxidant compounds (Everette et al. 2010).

Both DPPH and the Photochem method were used for the measurement of concentrations of antioxidant compounds present in the palm wine and palm vinegar by different mechanisms. By linearly correlating these two methods, the $R^{2}$ value was determined to be 0.94 . In other words, by measuring the antioxidant concentration with these two methods, we can determine that $94 \%$ of the results are similar in both cases. The very small measured 
differences were likely due to their different determination mechanism and the different standard antioxidant compound used.

\section{Conclusions}

In our study, we have highlighted the critical observation that $\mathrm{pH}$ is the most important factor for controlling photochemical properties of the products of the fermentation process. An optimum $\mathrm{pH}$ for a particular fermentation is not always suitable for polyphenol and flavonoid production as well as their stability. During the fermentation process, change in $\mathrm{pH}$ has an impact on the oxidative reaction of the phytochemicals. $\mathrm{pH} 5.5$ was found optimal for TPC $(125 \mathrm{mg} / \mathrm{L})$ and antioxidant activity $(127 \mathrm{mg} / \mathrm{L})$ in palm wine fermentation. $\mathrm{pH} 5.5$ was also optimal for TPC (168 mg/L) and antioxidant activity $(102 \mathrm{mg} / \mathrm{L})$ in palm vinegar. But the maximum TFC was found to be at $\mathrm{pH} 6.5$ in both palm wine and palm vinegar fermentations. Whether the individual antioxidant compounds are affected by changes in $\mathrm{pH}$ or not during the fermentation are not clear yet and need further research.

Acknowledgments The research work is financially supported by the Centre for Advanced studies (CAS I) program under the University Grants Commission (UGC), Govt. of India and Dept. of Food Processing Industries \& Horticulture, Govt. of West Bengal, India, Some facilities have been provided by the Centre for Medicinal Food \& Applied Nutrition of Jadavpur University, India. Thanks are also due to Dr. Cameron Keys from the Center for Nanotechnology in Society at Arizona State University for carefully proofreading and English editing the manuscript of the present paper.

Conflict of interest The authors declare that they have no conflict of interest for publishing this work in any publication house.

Open Access This article is distributed under the terms of the Creative Commons Attribution License which permits any use, distribution, and reproduction in any medium, provided the original author(s) and the source are credited.

\section{References}

Abe N, Murata T, Hirota A (1998) Novel DPPH radical scavengers, bisorbicillinol and demethyl-trichodimerol from fungus. Biosci Biotechnol Biochem 62:661-666

Ames BN (1983) Dietary carcinogens and anticarcinogens. Science 221:1256-1264

Amorati R, Pedulli GF, Cabrini L, Zambonin L, Landi L (2006) Solvent and $\mathrm{pH}$ effects on the antioxidant activity of caffeic and other phenolic acids. J Agric Food Chem 54:2932-2937

Borkowski T, Szumusiak H, Gliszczyńska-Świgło A, Rietjens IMCM, Tyrakowska B (2005) Radical scavenging capacity of wine anthocyanins is strongly $\mathrm{pH}$-dependent. J Agric Food Chem 53:5526-5534
Brand-Williams W, Cuvelier ME, Berset C (1995) Use of a free radical method to evaluate antioxidant activity. LWT 28:25-30

Coghe S, Benoot K, Delvaux F, Vanderhaegen B, Delvaux FR (2004) Ferulic acid release and 4- vinylguaiacal formation during brewing and fermentation: indications for feruloyl esterase activity in Saccharomyces cerevisiae. J Agric Food Chem 52:602-608

Di Stefano R, Guidoni S (1989) The analysis of total phenols in must and wines. Vignevivni 1:47-52

Dragsted LO (2003) Antioxidant actions of polyphenols in humans. Int J Vitam Nutr Res 73:112-119

Eberthardt MV, Lee CY, Liu RH (2000) Antioxidant activity of fresh apples. Nature 405:903-904

Esaki H, Onozaki H, Kawakishi S, Osawa T (1997) Antioxidant activity and isolation from Soybeans fermented with aspergillus spp. J Agric Food Chem 45:2020-2024

Everette J, Bryant QM, Green AM, Abbey YA, Wangila GW, Walker RB (2010) Thorough study of reactivity of various compound classes toward the Folin-Ciocalteu reagent. J Agric Food Chem 58:8139-8144

Gazi MR, Hoshikuma A, Kanda K, Murata A, Kato F (2001) Detection of free radical scavenging activity in yeast culture. Bull Fac Agric Saga Univ 86:67-74

Ghosh S, Chakraborty R, Raychaudhuri U (2012a) Optimizing Process Conditions for Palm (Borassus flabelliffer) Wine Fermentation using Response Surface Methodology. Int Food Res J 19:1633-1639

Ghosh S, Chakraborty R, Chatterjee G, Raychaudhuri U (2012b) Study on fermentation conditions of palm juice vinegar by response surface methodology and development of a kinetic model. Braz J Chem Eng 29:461-472

Grzymisławski M (2000) Physique of systems related to food bioavailability. In: Gawęcki J, Hryniewiecki L (eds) Human nutrition. Principals of nutritional science (in Polish). PWN, Warszawa, Poland, pp 56-72

Hernandez LF, Espinosa JC, Fernandez-Gonzalez M, Briones A (2003) $\beta$-Glucosidase activity in Saccharomyces cerevisiae wine strain. Int J Food Microbiol 80:171-176

Hertog MGL, Fesrens EJM, Hollman PCH, Katan MB, Kromhout D (1993) Dietary antioxidant flavonoids and risk of coronary heart disease: the Zutphen Elderly study. Lancet 342:1007-1011

Huang SW, Frankel EN, Schwarz K, German JB (1996) Effect of pH on antioxidant activity of $\alpha$-tocopherol and trolox in oil-in water emulsions. J Agric Food Chem 44:2496-2502

Ishikawa Y (1992) Development of new type of antioxidants from microbial origin. Jpn Oil Chem Soc 41:762-767

Jovanovic SV, Steenken S, Tosic M, Marjanovic B, Simic MG (1994) Flavonoids as antioxidants. JACS 116:4846-4851

Lemańska K, Szymusiak H, Tyrakowska B, Zieliński R, Soffers AEMF, Rietjens IMCM (2001) The influence of $\mathrm{pH}$ on the antioxidant properties and the mechanism of antioxidant action of hydroxyflavones. Free Radic Biol Med 31:869-881

Lin CH, Wei YT, Chou CC (2006) Enhenced antioxidative activity of Soyaben Koji prepared with various filamentous fungi. Food Microbiol 23:628-633

Lin M, Yen C (1999) Antioxidative ability of lactic acid bacteria. J Agric Food Chem 47:3661-3664

Lina QL, Akessonb B, Bergenstahlc B (2008) Effect of colloidal structures on the stability of five flavonoids with different hydrophilicity. Food Hydrocoll 22:700-705

Midori K, Tamiyoshi S, Kinuyo N, Masaaki T (2001) Effects of pH and Metal Ions on Antioxidative Activities of Catechins. Biosci Biotechnol Biochem 65:126-132

Muzolf M, Szymusiak H, Ska-Swiglo AG, Rietjens IMCM, Tyrakowska BE (2008) pH-Dependent radical scavenging capacity of green tea catechins. J Agric Food Chem 56:816-823

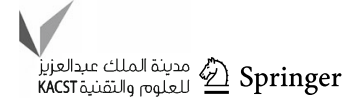


Namiki M (1990) Antioxidants/antimutagens in food. Crit Rev Food Sci Nutr 29:273-300

Osawa T, Namiki M, Kawakishi S (1990) Role of dietary antioxidants in protection against oxidative damage. Basic Life Sci 52:139-153

Singleton VL, Orthofer R, Lamuela-Raventos RM (1999) Analysis of total phenols and other oxidation substrates and antioxidants by mean of Folin-Ciocalteu reagent. Methods Enzymol 299: $152-178$

Swiglo AGN, Muzolf M (2007) pH-Dependent radical scavenging activity of folates. J Agric Food Chem 55:8237-8242

Van Acker SABE, De Groot MJ, Van den Berg DJ, Tromp MNJL, Kelder DOD, Van der Vijgh WJF, Bast A (1996) A quantum chemical explanation of the antioxidant activity of flavonoids. Chem Res Toxicol 9:1305-1312
Willcox JK, Ash JL, Catignani GL (2004) Antioxidants and prevention of chronic disease. Crit Rev Food Sci Nutr 44: 275-295

Yang CS, Landau JM, Huang MT, Newmark HL (2001) Inhibition of carcinogenesis by dietary polyphenolic compounds. Ann Rev Nutr 21:381-406

Zhishen J, Mengcheng T, Jianming W (1999) The determination of flavonoid contents in mulberry and their scavenging effects on superoxide radicals. Food Chem 64:555-559

Zhai H, Choi MJ, Arens-Corell M, Neudecker BA, Maibach HI (2003) A rapid, accurate, and facile method to quantify the antioxidative capacity of topical formulations. Skin Res Technol 9(3):254-256 